Disponível em:

http://editora.unoesc.edu.br/index.php/race

Race, Joaçaba, v. 15, n. 3, p. 1169-1192, set./dez. 2016

\title{
FATORES INFLUENCIADORES DA ADOÇÃO DE UM MÉTODO DE COSTING NA PERSPECTIVA DE PROFISSIONAIS EM CONTABILIDADE COM ATUAÇÃO NO SETOR INDUSTRIAL
}

Factors influencing the adoption of a cost method in professional perspective in accounting with operations in the industrial sector

Wenyka Preston Leite Batista da Costa

E-mail: wenykapreston@hotmail.com

Mestre em Administração pela Universidade Potiguar; Especialista em Auditoria Contábil pela Universidade do Estado do Rio Grande do Norte; Professora Auxiliar da Universidade do Estado do Rio Grande do Norte.

Jandeson Dantas da Silva

E-mail: jandeson.dantas@hotmail.com

Mestre em Administração e Controladoria pela Universidade Federal do Ceará; Pro-

fessor da Faculdades Nordeste

Rodrigo José Guerra Leone

E-mail: rodrigo.leone@gestorfp.com.br

Doutor em Engenharia de Sistemas e Computação pela Universidade Federal do Rio de Janeiro; Mestre em Matemática pela Universidade Federal da Paraíba; Professor do curso de Mestrado em Administração da Universidade Potiguar. Endereço para contato: Rua Seridó, 419, Petrópolis, 59020-010, Natal, Rio Grande do Norte, Brasil.

Maria Naiula Monteiro Pessoa

E-mail: naiula@ufc.br

Doutora em Engenharia de Produção pela Universidade Federal de Santa Catarina; Mestre em Economia pela Universidade Federal do Ceará; Professora Titular da Universidade Federal do Ceará.

Sergio Luiz Pedrosa Silva

E-mail: paideiaremoto@gmail.com

Mestre em Engenharia de Produção pela Universidade Federal de Santa Catarina; Professor adjunto da Universidade do Estado do Rio Grande do Norte e Chefe do

Departamento de Ciências Contábeis.

Artigo recebido em 26 de maio de 2015. Aceito em 13 de julho de 2016. 
Resumo

Os métodos de custeio são responsáveis por definir a forma pela qual os custos são apropriados aos seus portadores finais e possuem forte relevância na obtenção das informações gerenciais necessárias para os aspectos decisórios, na mensuração de estoques e na evidenciação dos resultados. Dessa forma, o período de adoção de um método de custeio é uma fase à qual uma entidade deve realizar análise detalhada dos objetivos pertinentes, buscando atender às necessidades dos diversos setores de forma eficiente e eficaz. Nesse sentido, o objetivo com esta pesquisa foi identificar os fatores que influenciam a adoção de um método de custeio nas empresas do setor industrial. A pesquisa possui natureza descritiva e quantitativa; a coleta de dados ocorreu por meio de um questionário eletrônico aplicado a 175 profissionais de contabilidade atuantes no setor industrial. Os resultados mostram que os fatores influenciadores da adoção de um método de custeio, em ordem de influência; são competitividade, gerenciamento, controle, legalidade, planejamento, apropriação, supervisão, comparabilidade, confiabilidade e precisão. Palavras-chave: Método de custeio. Contabilidade de custos. Adoção de um método.

\section{Abstract}

The costing methods are responsible for defining the way in which the costs are appropriate to their final carriers and have strong relevance in obtaining the management information necessary for decision-making aspects, in the measurement of inventories and in the disclosure of results. In this way, the period of adoption of a costing method is a stage at which an entity should perform detailed analysis of the relevant objectives, seeking to meet the needs of the many sectors efficiently and effectively. Accordingly, the objective with this research was to identify the factors influencing the adoption of a costing method in industrial companies. The research has descriptive and quantitative nature, the data was collected through an electronic questionnaire applied to 175 accounting professionals working in the industrial sector. The results show that the factors influencing the adoption of a costing method, in order of influence, are competitiveness, management, governance, legality, planning, ownership, supervision, comparability, reliability and accuracy.

Keywords: Costing method. Costing accounting. Adoption of a method.

\section{INTRODUÇÃO}

As informações contábeis caracterizam-se como uma ferramenta de auxílio à gerência administrativa de uma organização, tendo ênfase no processo decisório. No setor industrial, a contabilidade destaca-se, sobretudo, na gestão de custos, que representa um diferencial nas atitudes negociáveis. Na concepção de Martins (2003), a contabilidade de custos surgiu com a revolução industrial, quando a contabilidade 
financeira não conseguia suprir a necessidade das indústrias com ênfase na formação de preço de venda dos produtos e dos serviços. Para suprir essas necessidades, os métodos de custeio possuem forte relevância, uma vez que são responsáveis por realizar a alocação dos custos envolvidos no processo de produção. Wickert (2004) afirma que os métodos de custeio mais conhecidos pela comunidade acadêmica e operacional são: custeio baseado em atividades (Activity Based Consting - ABC), custeio por absorção, custeio variável e custeio padrão. Todos esses métodos apresentam vantagens e desvantagens que devem ser avaliadas de acordo com a necessidade de cada organização. Entretanto, os métodos de custeio devem ser adequados à real situação da empresa, de modo que sejam relevantes e confiáveis no processo de tomada de decisão.

Apesar de tantos benefícios trazidos para as organizações, Pompermayer (2000) destaca que uma das grandes dificuldades ocorridas no processo de adoção de um método de custeio está na falta de entendimento dos conceitos, das terminologias dos custos e da relevância de um método, por parte dos gestores das empresas. A maioria busca atender apenas parte das necessidades da organização, como, por exemplo, a legislação fiscal, comprometendo, assim, a eficácia e eficiência do método, que não será capaz de demonstrar a real situação da entidade. Dessa forma, torna-se relevante evidenciar quais os fatores influenciadores da adoção de um método de custeio em empresas do setor industrial na perspectiva de profissionais em contabilidade.

Nesta pesquisa tem-se como objetivo geral identificar os fatores influenciadores da adoção de um método de custeio em empresas do setor industrial na perspectiva de profissionais em contabilidade, e como objetivos específicos pretende-se encontrar e nomear os agrupamentos de fatores influentes para a adoção de um método de custeio, na ótica dos profissionais contábeis com atuação no setor industrial, além de evidenciarem-se os fatores influenciadores da adoção de um método de custeio com maior grau de importância.

De maneira específica, o trabalho dá continuidade à pesquisa realizada por Fiorese (2005) na qual se realizou uma análise comparativa dos métodos de custeio nas indústrias metalúrgicas. O autor identificou na pesquisa alguns aspectos que precisam ser aprofundados e vistos de forma holística; entre estes destacam-se a sugestão de investigar a necessidade da informação que cada gestor possui antes de definir qual método de custeio deve ser adotado pela organização. Sendo esse o objetivo geral do presente estudo, optou-se por identificar esse método na perspectiva de profissionais da contabilidade, pois eles, em sua grande maioria, são os responsáveis pela adoção dos métodos de custeio. 
A realização deste trabalho justifica-se por sua relevância em evidenciar aos administradores que a identificação das variáveis que influenciam a adoção de um método de custeio traz benefícios para a organização, auxiliando o planejamento, possibilitando oportunidades de crescimento para a empresa, colocando-a em posicionamento estratégico perante as demais instituições do mercado. De acordo com Kaspczak, Scandelari e Francisco (2008), os métodos de custeio são apontados como ferramentas capazes de oferecer informações relativas à estrutura de custos, principalmente em organizações industriais, que apresentam grande complexidade na gestão de custos.

Os métodos de custeio representam a parte da contabilidade de custos, na qual os dados são processados, gerando informações para a tomada de decisões, por esse motivo a fase da adoção de um método de custeio é relevante, pois uma vez que não atenda às necessidades da organização poderá comprometer seriamente o comportamento dos seus resultados (FIORESE, 2005).

\section{REFERENCIAL TEÓRICO}

\subsection{MÉTODOS DE CUSTEIO}

Em qualquer organização, no processo de tomada de decisões, existem ferramentas que auxiliam os gestores a tornar as organizações mais competitivas em seu segmento de atuação. O sistema de custos é uma ferramenta que fornece informações sobre a estrutura de custos de determinada organização. Nesse sentido, trata-se de uma ferramenta que pode ser utilizada no âmbito interno de uma organização nos níveis: estratégico, tático e operacional. No nível operacional ocorre a coleta dos dados, no tático os dados são diferenciados e classificados transformando-se em informações que, provavelmente, serão utilizadas pelo nível estratégico para a tomada de decisões estratégicas, como, por exemplo: decidir qual o melhor mix de produtos, cortar ou não a produção de um produto, controlar ou reduzir custos, entre outros fatores relevantes em uma organização (KASPCZAK; SCANDELARI; FRANCISCO, 2008).

O sistema de informação deve disponibilizar os custos precisos dos produtos para fixação de preços, lançamento de novos produtos, eliminação de produtos obsoletos e melhorias no desempenho dos produtos para competir com os concorrentes. Nota-se que os métodos de custeio apresentam papel fundamental no sistema de informações, pois como vistos, são eles que processam e geram informações para os gestores. A forma esquemática e a metodologia utilizada pelos diversos métodos de 
custeio contemplam a problemática de alocação de custos e despesas aos produtos ou serviços que estão sendo produzidos pela organização (FIORESE, 2005).

Para Wickert (2004), os métodos de custeio mais conhecidos pela comunidade acadêmica e operacional são: custeio baseado em atividades (Activity Based Consting $-A B C$ ), custeio por absorção, custeio variável e custeio padrão, que são vistos de forma mais aprofundada nos próximos tópicos.

\subsubsection{Método de custeio baseado em atividades (Activity Baed Consting - ABC)}

$\mathrm{O} A B C$ é uma ferramenta que permite uma melhor visualização dos custos por meio da análise das atividades executadas pela empresa e suas respectivas relações com os produtos. Nesse método é necessário identificar os direcionadores que podem ser: Direcionadores de Recursos e Direcionadores de Atividades. Sendo o primeiro responsável por determinar a ocorrência de uma atividade, identificar a maneira com que as atividades consomem recursos e como serve para custear as atividades; já o segundo busca identificar a maneira como os produtos consomem atividades e serve para custear os produtos (AZEVEDO; GOUVÊA; OLIVEIRA, 2006; MAUAD; PAMPLONA, 2003).

O sistema de custeio $A B C$ possui uma maneira própria de apropriar seus custos, pois sua metodologia não realiza agregação entre custos e despesas, mas separa as atividades que adicionam valor e as que não adicionam valor aos produtos ou serviços fabricados. As atividades que agregam valor são aquelas que absorvem recursos os transformando em produtos ou serviços compatíveis com as necessidades dos clientes. Esse custeio pode ser dividido em dois estágios; o primeiro preocupa-se em identificar os recursos existentes na organização, e o segundo focaliza em identificar as atividades desempenhadas na produção, para realizar a devida alocação dos custos.

\subsubsection{Método de custeio absorção}

O método de custeio por absorção consiste na apropriação de todos os gastos realizados na produção dos produtos desenvolvidos pela organização. O diferencial desse método de custeio entre os demais é a realização da alocação das despesas apenas nos demonstrativos de resultados. Esse método busca custear o produto, atribuindo-lhe, também, parte do custo fixo, bem como consiste na apropriação de todos os custos de produção aos produtos elaborados, de forma direta e indireta (rateios). O princípio básico do método de custeio por absorção é fragmentar a empresa em 
inúmeras áreas funcionais, os chamados centros de custos, apropriando os custos indiretos (fixos e variáveis) no custo do produto, proporcionalmente ao esforço de fabricação de cada produto, permitindo um maior controle na produção. Assim, a metodologia do custeio por absorção consiste nas seguintes etapas: inicialmente ocorre a separação de custos e despesas, logo após tem-se a apropriação dos custos diretos e indiretos aos produtos, e por fim há a apropriação mediante rateio dos custos indiretos dos produtos (REBELATTO; ARAMAYO; ALMEIDA, 2006).

Esse custeio consiste em ser um método tradicional que também pode ser denominado Custeio Integral, pois realiza a apropriação integral de todos os custos, sendo eles diretos, indiretos, fixos ou variáveis que ocorram no processo produtivo de um produto ou serviço. Por esse motivo, os custos passam a ser classificados como custos totais, os custos diretos absorvem também os custos indiretos, classificados por critérios simples e convencionais. Para os produtos e processos, são contabilizados os custos diretos, recebendo a devida parcela, mediante a forma de rateio dos custos indiretos onde estão sendo realizados (CASTRO, 2011). Para Fiorese (2005), um dos pontos fortes que garantem a adoção desse custeio está no fato de atender à Legislação Fiscal Brasileira e estar de acordo com os Princípios Fundamentais da Contabilidade aplicados a custos, além de proporcionar informações à gerência para as finalidades de formação de preços de vendas, objetivando a recuperação dos custos incorridos em determinados períodos.

\subsubsection{Método de custeio variável}

O custeio variável pode ser compreendido por se preocupar apenas em apropriar os custos e despesas variáveis, descartando, de certa forma, custos e despesas fixas. Os custos e as despesas fixas não são a eles apropriados, não existindo, assim, nesse sistema, os conceitos de custo total e resultado do produto, mas um custo variável e uma margem de contribuição do produto, da mercadoria ou do serviço desenvolvido pela organização em determinado período. Essa margem de contribuição decorre do comparativo de venda, com uma visão mais direcionada ao mercado e não tanto ao custo dos produtos e serviços (BERTÓ; BEULK, 2006).

O método de custeio atende plenamente à expectativa da organização referente ao processo decisório, oferecendo informações tempestivas e confiáveis, entretanto esse método não é aceito pela Legislação Fiscal Brasileira e nem pelas Normas Brasileiras de Contabilidade. Como visto, a metodologia utilizada por esse custeio atribui alocação apenas aos custos variáveis incorridos no processo produtivo, in- 
fringindo, assim, os Princípios Fundamentais da Contabilidade, mais precisamente o princípio da Competência, no qual é afirmado que todas as receitas e despesas devem ser registradas no período em que ocorreram sem haver diferenciação entre classificação fixa e variável. Por isso, a Demonstração de Resultado e o Balanço Patrimonial devem ser avaliados com base nesse método e não são aceitos para usuários externos, somente para internos por serem fortes aliados nas decisões da organização (ROSA, 2006; CATELLI; PEREIRA; VASCONCELOS, 2001).

\subsubsection{Método de custeio padrão}

O método de custeio baseado em custo padrão preocupa-se em delinear o quanto deveria custar certa produção, considerando-se certas condições normais ou ideais. Esses padrões podem ser estabelecidos para matérias, mão de obra, custos indiretos, materiais, entre outros fatores passíveis de modificação, em que se deve destacar especificação, quantidade, preço de custo, taxa de aproveitamento, perdas naturais, entre outros fatores. Esse custeio é uma base de comparação para o custo realizado e somente tem, de fato, utilidade à medida que a empresa o utiliza e dispõe de um bom sistema de apuração do custo realizado. Periasamy (2010) destaca que o custeio padrão nada mais é que uma técnica da contabilidade de custos que compara o custo padrão de cada produto ou serviço com o custo real, determinando a eficiência da operação de modo que qualquer ação corretiva pode ser tomada imediatamente. Tais alterações podem ser originadas por diversos fatores, como: mudanças nas especificações do produto quanto ao consumo de matérias-primas de baixa qualidade levando a uma maior quantidade de perda, aumento de custos das matérias-primas pelos fornecedores, entre outros (CRUZ, 2010; KOHLER, 1975).

Na concepção de Barbosa (2004) o método de custeio padrão visa quantificar os custos relacionados à matéria-prima e insumos, baseado em informações de anos anteriores para controlar preços dos insumos necessários no processo produtivo, uma vez que se tem a quantidade a ser utilizada já determinada pelos padrões. Assim, o custo padrão é o custo determinado como o custo normal de um produto. Esse método de custeio é elaborado considerando um cenário de bom desempenho operacional, porém atentando a eventuais deficiências existentes nos materiais e insumos de produção, na mão de obra, etc. (PEREZ JÚNIOR; OLIVEIRA; COSTA, 2001). 


\section{METODOLOGIA}

A pesquisa se caracteriza quanto aos meios de investigação como pesquisa de campo, considerando-se a investigação empírica com profissionais de contabilidade atuantes no setor industrial, cadastrados no Conselho Regional de Contabilidade do Estado do Rio Grande do Norte.

Para alcançar os objetivos propostos no presente estudo, foi escolhido o método de abordagem quantitativa, em virtude de os dados obtidos na pesquisa serem analisados por meio dos métodos estatísticos, possibilitando, assim, identificar os fatores influenciadores da adoção de um método sobre a perspectiva de contadores e técnicos em contabilidade com atuação no setor industrial. $\mathrm{O}$ universo da pesquisa foi composto por contadores e técnicos em contabilidade cadastrados no Conselho Regional de Contabilidade do Estado do Rio Grande do Norte. No que se refere à amostra, foi determinada de acordo com o número de variáveis identificadas na presente pesquisa. Segundo Hair Júnior et al. (2009), multiplicando-se o número de variáveis identificadas por, no mínimo, cinco vezes, obtém-se a amostra mínima de sujeitos. Assim, foram identificadas 35 variáveis para análise, o que representa uma amostra de 175 sujeitos respondentes.

Os dados nesta pesquisa foram tratados com estatística descritiva (frequências, médias) e análise fatorial. Para a análise fatorial, utilizou-se a técnica de análise dos componentes principais, apoiada nos testes KMO e esfericidade de Bartlett, em que foi definido o autovalor maior que um como critério para a quantidade dos fatores, aos quais influenciam a adoção de um método de custeio. Os fatores gerados pela análise fatorial foram identificados e nomeados em razão das variáveis que os compõem. As respostas foram, então, substituídas pelos valores dos fatores, e a média dos fatores foi utilizada para identificar a ordem de importância, além de identificar as variáveis com maior influência na adoção dos métodos de custeio.

As variáveis relacionadas com adoção de um método de custeio podem ser encontradas em contribuições de vários autores. Foram identificadas 35 variáveis, posteriormente agrupadas em dimensões, geralmente, relacionadas com o foco de estudo. Após o levantamento realizado, as variáveis encontradas na literatura foram agrupadas com base na percepção de Marcos e Naia (2001), os quais destacam que a contabilidade de custos, bem como os métodos de custeio se concentram no planejamento e no controle das operações, como suporte para a tomada de decisão e a alocação de custos de produção das atividades desenvolvidas por uma organização. 
Nascimento et al. (2003) afirmam que, ao definirem um método de custeio, as indústrias buscam adotar um método que seja aplicável ao processo produtivo, este deve atender em grande parte ao aspecto gerencial com o objetivo de fornecer informações úteis para fins de planejamento. O planejamento caracteriza-se como uma das grandes preocupações da organização, pois é por meio deste que são formulados possíveis direcionamentos que serão seguidos pela entidade. Nesse sentido, a adoção de um método de custeio possibilita diversas formas de planejamento que visam auxiliar no gerenciamento, desenvolvimento ou adaptações das operações desempenhadas. Dessa forma, nos diversos métodos de custeio encontram-se variáveis de planejamento de operações que explicam a sua adoção (Quadro 1).

Quadro 1 - Variáveis do grupo Planejamento das operações

\begin{tabular}{|c|c|l|l|l|}
\hline No & $\begin{array}{c}\text { MÉTO- } \\
\text { DO }\end{array}$ & VARIÁVEL & \multicolumn{1}{|c|}{ EXPLICAÇÃo } & \multicolumn{1}{c|}{ AUTORES } \\
\hline V01 & Absorção & $\begin{array}{l}\text { Margem de } \\
\text { lucro desejada. }\end{array}$ & $\begin{array}{l}\text { Leva à margem de lucro de- } \\
\text { sejada para o produto, sendo } \\
\text { possível planejar a margem } \\
\text { de lucro para os próximos } \\
\text { períodos. }\end{array}$ & $\begin{array}{l}\text { Gonçalves, Procópio e Concen- } \\
\text { za (1998), Megliorini (2007), } \\
\text { Hongrem, Foster e Data (2000) } \\
\text { e Longenecker, Moore e Petty } \\
\text { (1997). }\end{array}$ \\
\hline V02 & Variável & $\begin{array}{l}\text { Planejamento de } \\
\text { custos, volume } \\
\text { e lucro. }\end{array}$ & $\begin{array}{l}\text { Auxilia no processo de plane- } \\
\text { jamento que envolva custos, } \\
\text { volume e lucro dos produtos. }\end{array}$ & $\begin{array}{l}\text { Esteves (2010), Maher (2001), } \\
\text { Garrison e Norenn (2001) e } \\
\text { Bornia, (2002). }\end{array}$ \\
\hline V03 & Variável & $\begin{array}{l}\text { Ponto de equi- } \\
\text { líbrio dos pro- } \\
\text { dutos. }\end{array}$ & $\begin{array}{l}\text { É possível calcular o ponto } \\
\text { de equilíbrio dos produtos, } \\
\text { planejando quanto a empresa } \\
\text { deve vender para cobrir as } \\
\text { despesas e obter lucro. }\end{array}$ & $\begin{array}{l}\text { Motta (2000), Maher (2001) e } \\
\text { Vanderbeck (2001). }\end{array}$ \\
\hline
\end{tabular}

Fonte: os autores.

Carareto et al. (2006) destacam que a gestão de custos, bem como a utilização de métodos de custeio caracterizam-se como ferramentas que buscam oferecer às empresas informações que lhes permitam se manterem no mercado, com produtos de qualidade a um custo menor do que aquele oferecido pelos concorrentes. Nesse contexto, a análise da relação de custo, volume e lucro e a aplicação de mecanismos, como margem de contribuição, ponto de equilíbrio contábil, entre outros, são instrumentos que podem contribuir significativamente à tomada de decisão, sendo esta caracterizada como um dos fatores a serem observados para a adoção de determinado método (Quadro 2). 
Quadro 2 - Suporte para a tomada de decisão

\begin{tabular}{|c|c|c|c|c|}
\hline $\mathbf{N}^{\circ}$ & MÉTODO & VARIÁVEL & EXPLICAÇÃO & AUTORES \\
\hline V04 & $\mathrm{ABC}$ & $\begin{array}{l}\text { Ferramenta geren- } \\
\text { cial por meio dos } \\
\text { direcionadores de } \\
\text { custos. }\end{array}$ & $\begin{array}{l}\text { Importante ferramenta gerencial, } \\
\text { pois ao enfatizar a alocação dos } \\
\text { custos indiretos por meio de } \\
\text { direcionadores de custos fornece } \\
\text { informações para a tomada de } \\
\text { decisões. }\end{array}$ & $\begin{array}{l}\text { Souza, Avelar e Pavione } \\
\text { (2011), Mauad e Pam- } \\
\text { plona (2003) }\end{array}$ \\
\hline V05 & $\mathrm{ABC}$ & $\begin{array}{l}\text { Vantagem compe- } \\
\text { titiva. }\end{array}$ & $\begin{array}{l}\text { O método se caracteriza como } \\
\text { uma vantagem competitiva, } \\
\text { oferecendo informações que } \\
\text { permitem a tomada de decisões } \\
\text { gerenciais. }\end{array}$ & $\begin{array}{l}\text { Frossard (2003) e Naka- } \\
\text { gawa (1994). }\end{array}$ \\
\hline V06 & Variável & $\begin{array}{l}\text { Flexibilizar o pro- } \\
\text { cesso de tomada } \\
\text { de decisões. }\end{array}$ & $\begin{array}{l}\text { Principal objetivo: flexibilizar o } \\
\text { processo de tomada de decisões. }\end{array}$ & $\begin{array}{l}\text { Morelli (2007), Mosco- } \\
\text { ve, Simkin e Bagranoff } \\
\text { (2002) e O’Brien (2004). }\end{array}$ \\
\hline V07 & Variável & $\begin{array}{l}\text { Calcular a mar- } \\
\text { gem de contri- } \\
\text { buição. }\end{array}$ & $\begin{array}{l}\text { Por meio do cálculo da margem } \\
\text { de contribuição, podendo decidir } \\
\text { excluir ou melhorar determina- } \\
\text { dos produtos que não oferecem } \\
\text { mais lucro para a empresa. }\end{array}$ & $\begin{array}{l}\text { Esteves (2010), Souza } \\
\text { (2007) e Motta (2000). }\end{array}$ \\
\hline V08 & Variável & $\begin{array}{l}\text { Tomada de } \\
\text { decisões que } \\
\text { envolvam custos, } \\
\text { volume e lucro. }\end{array}$ & $\begin{array}{l}\text { Auxilia na tomada de decisões } \\
\text { que envolvam custos, volume e } \\
\text { lucro dos produtos. }\end{array}$ & $\begin{array}{l}\text { Esteves (2010), Maher } \\
\text { (2001), Garrison e No- } \\
\text { renn e Woreen (2001) e } \\
\text { Bornia (2002). }\end{array}$ \\
\hline V09 & Variável & $\begin{array}{l}\text { Oferece informa- } \\
\text { ções tempestivas } \\
\text { e confiáveis. }\end{array}$ & $\begin{array}{l}\text { No processo decisório, o método } \\
\text { de custeio atende plenamente à } \\
\text { expectativa das organizações, } \\
\text { oferecendo informações tempes- } \\
\text { tivas e confiáveis. }\end{array}$ & $\begin{array}{l}\text { Rosa (2006), Catelli, } \\
\text { Pereira e Vasconcelos } \\
\text { (2001). }\end{array}$ \\
\hline
\end{tabular}

Fonte: os autores.

Na percepção de Morozini et al. (2001), uma das principais funções de um método de custeio é o controle das diversas operações ocorridas no processo produtivo de uma organização. Mediante esse controle é possível estabelecer padrões e orçamentos entre as rotinas dos diversos segmentos. Outro fator que pode ser desenvolvido em decorrência do controle são comparações entre os custos orçados e os custos reais, que posibilitam a realização de provisões de eventos futuros para posterior acompanhamento. Vários autores destacam atividades decorrentes do controle das operações, como pode ser observado no Quadro 3. Esses fatores podem ser 
classificados como possíveis variáveis influentes para a adoção de um determinado método de custeio.

Quadro 3 - Variáveis do grupo Controle das Operações

\begin{tabular}{|c|c|c|c|c|}
\hline $\mathbf{N}^{\mathbf{o}}$ & $\begin{array}{l}\text { MÉ- } \\
\text { TODO }\end{array}$ & VARIÁVEL & EXPLICAÇÃO DA & AUTORES \\
\hline V10 & $\mathrm{ABC}$ & $\begin{array}{l}\text { Acompanhamento } \\
\text { da perspectiva do } \\
\text { cliente. }\end{array}$ & $\begin{array}{l}\text { Acompanha os custos na perspectiva do } \\
\text { cliente. }\end{array}$ & $\begin{array}{l}\text { Frossard (2003) } \\
\text { e Carmo (2011). }\end{array}$ \\
\hline V11 & $\mathrm{ABC}$ & $\begin{array}{l}\text { Eliminar e reduzir } \\
\text { custos que não } \\
\text { adicionam valor ao } \\
\text { produto. }\end{array}$ & $\begin{array}{l}\text { Método de custeio: elimina custos que não } \\
\text { adicionam valor ao produto e que podem } \\
\text { ser eliminados ou reduzidos sem afetar } \\
\text { atributos desse produto. }\end{array}$ & $\begin{array}{l}\text { Frossard (2003) } \\
\text { e Carmo (2011). }\end{array}$ \\
\hline V12 & $\begin{array}{l}\text { Absor- } \\
\text { ção }\end{array}$ & $\begin{array}{l}\text { Fragmenta a em- } \\
\text { presa em centros de } \\
\text { custos. }\end{array}$ & $\begin{array}{l}\text { O princípio básico do método de custeio } \\
\text { por absorção visa fragmentar a empresa } \\
\text { em inúmeras áreas funcionais, os chama- } \\
\text { dos centros de custos. }\end{array}$ & $\begin{array}{l}\text { Rebelatto; Ara- } \\
\text { mayo e Almeida } \\
(2006) \text {. }\end{array}$ \\
\hline V13 & $\mathrm{ABC}$ & $\begin{array}{l}\text { Acompanhamento } \\
\text { das atividades ope- } \\
\text { racionais e finan- } \\
\text { ceiras. }\end{array}$ & $\begin{array}{l}\text { Acompanha os custos incorridos nas ativi- } \\
\text { dades operacionais da organização. }\end{array}$ & $\begin{array}{l}\text { Frossard (2003) } \\
\text { e O’Guin } \\
\text { (1991). }\end{array}$ \\
\hline V14 & $\begin{array}{l}\text { Variá- } \\
\text { vel }\end{array}$ & $\begin{array}{l}\text { Avaliar e controlar } \\
\text { estratégias. }\end{array}$ & $\begin{array}{l}\text { Oferece informações que podem ser utili- } \\
\text { zadas para avaliar e controlar estratégias } \\
\text { da empresa. }\end{array}$ & $\begin{array}{l}\text { Motta (2000) } \\
\text { e Scigliano, } \\
\text { (2011). }\end{array}$ \\
\hline V15 & Padrão & $\begin{array}{l}\text { Determina as esti- } \\
\text { mativas de custos. }\end{array}$ & $\begin{array}{l}\text { Busca eficiência em determinação da } \\
\text { estimativa de custos. }\end{array}$ & $\begin{array}{l}\text { Cruz (2010), Pe- } \\
\text { riasamy (2010) e } \\
\text { Kohler (1975). }\end{array}$ \\
\hline V16 & Padrão & $\begin{array}{l}\text { Comparação do } \\
\text { custo realizado e } \\
\text { previsto. }\end{array}$ & $\begin{array}{l}\text { Por meio do comparativo com a produção } \\
\text { anterior, o método serve de base de com- } \\
\text { paração e controle do custo realizado com } \\
\text { o previsto. }\end{array}$ & $\begin{array}{l}\text { Cruz (2010), Pe- } \\
\text { riasamy (2010) e } \\
\text { Kohler (1975). }\end{array}$ \\
\hline V18 & Padrão & $\begin{array}{l}\text { Acompanhamento } \\
\text { na produção. }\end{array}$ & $\begin{array}{l}\text { Realiza acompanhamento e controle da } \\
\text { produção por meio dos fatores internos e } \\
\text { externos. }\end{array}$ & $\begin{array}{l}\text { Kraemer (1995) } \\
\text { e Robles Junior } \\
(2009) \text {. }\end{array}$ \\
\hline V19 & Padrão & $\begin{array}{l}\text { Controle na pro- } \\
\text { dução. }\end{array}$ & $\begin{array}{l}\text { Realiza controle na produção por meio } \\
\text { dos fatores internos e externos. }\end{array}$ & $\begin{array}{l}\text { Kraemer (1995) } \\
\text { e Robles Junior } \\
(2009)\end{array}$ \\
\hline V20 & Padrão & $\begin{array}{l}\text { Aprimoramento dos } \\
\text { controles da organi- } \\
\text { zação. }\end{array}$ & $\begin{array}{l}\text { Uma das vantagens desse método de } \\
\text { custeio está nos padrões desempenho e de } \\
\text { consumos que podem servir como base } \\
\text { para um aprimoramento de controles nas } \\
\text { organizações. }\end{array}$ & $\begin{array}{l}\text { Fandanelli } \\
\text { (2007) e Sciglia- } \\
\text { no (2011). }\end{array}$ \\
\hline
\end{tabular}

Fonte: os autores.

Os métodos de custeio referem-se às formas pelas quais os custos são registrados e transferidos internamente na entidade, identificando os custos dos estoques de produção em andamento e de produtos acabados, realizando, assim, alocação eficiente e eficaz dos custos. Nesse contexto, uma das principais variáveis na adoção de um método de custeio está na forma de alocação de custos de produção (Quadro 4), tendo como objetivo controlar adequadamente a classificação dos custos envolvidos nas diversas operações da entidade (BRUNI; FAMÁ, 2009). 
Wenyka Preston Leite Batista da Costa et al.

Quadro 4 - Variáveis do grupo Alocação de custos

\begin{tabular}{|c|c|c|c|c|}
\hline $\mathbf{N}^{\mathbf{o}}$ & MÉTODO & VARIÁVEL & EXPLICAÇÃO & AUTORES \\
\hline V17 & Padrão & Controlar preços de insumos. & $\begin{array}{l}\text { Por meio da comparação } \\
\text { com a produção anterior é } \\
\text { possível controlar os preços } \\
\text { dos insumos. }\end{array}$ & $\begin{array}{l}\text { Barbosa (2004) } \\
\text { e Perez Junior; } \\
\text { Oliveira e Costa } \\
\text { (2001). }\end{array}$ \\
\hline V21 & $\mathrm{ABC}$ & $\begin{array}{l}\text { Não realiza rateios arbitrá- } \\
\text { rios. }\end{array}$ & $\begin{array}{l}\text { Os rateios arbitrários não } \\
\text { são realizados, pois não são } \\
\text { utilizados como ferramenta } \\
\text { gerencial. }\end{array}$ & $\begin{array}{l}\text { Lourenço (2009), } \\
\text { Brimson (1996) } \\
\text { e Nakagawa } \\
\text { (1994). }\end{array}$ \\
\hline V22 & $\mathrm{ABC}$ & $\begin{array}{l}\text { Identificação dos custos por } \\
\text { atividade. }\end{array}$ & $\begin{array}{l}\text { A superioridade do uso do } \\
\text { método de custeio por ativi- } \\
\text { dade está por realizar iden- } \\
\text { tificação que faz dos custos } \\
\text { por atividade. }\end{array}$ & $\begin{array}{l}\text { Silva (2011) e } \\
\text { Baker (1998). }\end{array}$ \\
\hline V23 & $\mathrm{ABC}$ & $\begin{array}{l}\text { Reduz distorções no rateio } \\
\text { dos custos indiretos. }\end{array}$ & $\begin{array}{l}\text { Reduz distorções causadas } \\
\text { pelo arbitramento do rateio } \\
\text { dos custos indiretos da } \\
\text { fabricação. }\end{array}$ & $\begin{array}{l}\text { Azevedo, Gouvêa } \\
\text { e Oliveira (2006) } \\
\text { e Mauad e Pam- } \\
\text { plona (2003). }\end{array}$ \\
\hline V24 & Absorção & $\begin{array}{l}\text { Alocação das despesas } \\
\text { apenas nos demonstrativos } \\
\text { de resultado. }\end{array}$ & $\begin{array}{l}\text { Realiza alocação das despe- } \\
\text { sas apenas nos demonstrati- } \\
\text { vos de resultados. }\end{array}$ & $\begin{array}{l}\text { Rebelatto; Ara- } \\
\text { mayo e Almeida } \\
(2006) \text {. }\end{array}$ \\
\hline V25 & Absorção & $\begin{array}{l}\text { Apropriação dos custos } \\
\text { indiretos (fixos e variáveis) } \\
\text { no custo do produto. }\end{array}$ & $\begin{array}{l}\text { Apropria os custos indiretos } \\
\text { (fixos e variáveis) no custo } \\
\text { do produto, proporcional- } \\
\text { mente ao esforço de fabrica- } \\
\text { ção de cada produto. }\end{array}$ & $\begin{array}{l}\text { Rebelatto, Ara- } \\
\text { mayo e Almeida } \\
(2006) \text {. }\end{array}$ \\
\hline V26 & Absorção & $\begin{array}{l}\text { Apropriação integral de } \\
\text { todos os custos. }\end{array}$ & $\begin{array}{l}\text { Possui característica de } \\
\text { apropriação integral de } \\
\text { todos os custos, sendo eles } \\
\text { diretos, indiretos, fixos e } \\
\text { variáveis. }\end{array}$ & $\begin{array}{l}\text { Castro (2011), } \\
\text { Periasamy (2010) } \\
\text { e Rebelatto, Ara- } \\
\text { mayo e Almeida, } \\
\text { (2006). }\end{array}$ \\
\hline V27 & Absorção & $\begin{array}{l}\text { Apuração de desempenho } \\
\text { unitário. }\end{array}$ & $\begin{array}{l}\text { Utilizado pelas organizações } \\
\text { para apuração do desempe- } \\
\text { nho unitário. }\end{array}$ & $\begin{array}{l}\text { Castro (2011) } \\
\text { e Periasamy } \\
(2010) .\end{array}$ \\
\hline V28 & Absorção & $\begin{array}{l}\text { Recuperar todos os custos } \\
\text { (diretos e indiretos) }\end{array}$ & $\begin{array}{l}\text { Esse método de custeio é } \\
\text { indicado para ser utilizado, } \\
\text { pois recupera todos os cus- } \\
\text { tos diretos e indiretos. }\end{array}$ & $\begin{array}{l}\text { Gonçalves, Pro- } \\
\text { cópio e Concenza } \\
\text { (1998). }\end{array}$ \\
\hline V29 & Absorção & Atende à Legislação Fiscal. & $\begin{array}{l}\text { Um dos pontos fortes que } \\
\text { garantem a adoção desse } \\
\text { custeio está no fato de aten- } \\
\text { der a Legislação Fiscal. }\end{array}$ & $\begin{array}{l}\text { Fiorese (2005) } \\
\text { e Nascimento } \\
(2001) .\end{array}$ \\
\hline V30 & Absorção & $\begin{array}{l}\text { Está de acordo com os } \\
\text { Princípios Fundamentais da } \\
\text { Contabilidade. }\end{array}$ & $\begin{array}{l}\text { Um dos pontos fortes que } \\
\text { garantem a adoção desse } \\
\text { custeio está de acordo com } \\
\text { os Princípios Fundamentas } \\
\text { da Contabilidade. }\end{array}$ & $\begin{array}{l}\text { Fiorese (2005) } \\
\text { e Nascimento } \\
\text { (2001). }\end{array}$ \\
\hline V31 & Variável & $\begin{array}{l}\text { Somente os custos variáveis } \\
\text { são alocados aos produtos. }\end{array}$ & $\begin{array}{l}\text { Somente os custos variá- } \\
\text { veis são considerados para } \\
\text { alocação dos produtos ou } \\
\text { serviços desenvolvidos. }\end{array}$ & Panarella (2010). \\
\hline
\end{tabular}




\begin{tabular}{|c|l|l|l|l|}
\hline No & MÉTODO & \multicolumn{1}{c|}{ VARIÁVEL } & \multicolumn{1}{c|}{ EXPLICAÇÃo } & \multicolumn{1}{c|}{ AUTORES } \\
\hline V32 & Padrão & $\begin{array}{l}\text { Delinear custo certo da } \\
\text { produção }\end{array}$ & $\begin{array}{l}\text { O sistema de custos baseado } \\
\text { no custo padrão preocupa-se } \\
\text { em delinear quanto deveria } \\
\text { custar certa produção. }\end{array}$ & $\begin{array}{l}\text { Cruz (2010) e } \\
\text { Kohler (1975). }\end{array}$ \\
\hline V33 & Padrão & $\begin{array}{l}\text { Oferece maior rigor técnico } \\
\text { na estimativa do custo. }\end{array}$ & $\begin{array}{l}\text { Diferencia-se de um custo } \\
\text { meramente estimado em } \\
\text { razão de apresentar maior } \\
\text { rigor técnico na estimativa } \\
\text { de custos. }\end{array}$ & $\begin{array}{l}\text { Cruz (2010) e } \\
\text { Kohler (1975). }\end{array}$ \\
\hline V34 & Padrão & $\begin{array}{l}\text { Realiza sistema de apuração } \\
\text { do custo realizado. }\end{array}$ & $\begin{array}{l}\text { Esse método de custeio } \\
\text { realiza apuração do custo } \\
\text { realizado. }\end{array}$ & $\begin{array}{l}\text { Cruz (2010) e } \\
\text { Kohler (1975). }\end{array}$ \\
\hline V35 & Padrão & $\begin{array}{l}\text { Sistema de identificação e } \\
\text { acumulação de custos. }\end{array}$ & $\begin{array}{l}\text { O sistema de identificação } \\
\text { e acumulação de custos tem } \\
\text { por finalidade identificar os } \\
\text { valores e os acumular de } \\
\text { acordo com alguns critérios } \\
\text { estabelecidos. }\end{array}$ & Fiorese (2005). \\
\hline
\end{tabular}

Fonte: os autores.

\section{RESULTADO}

Para se alcançarem dos objetivos da pesquisa, foi utilizada a ferramenta estatística análise fatorial, a qual após a rotação e os testes de adequação da amostra evidenciou 10 fatores, que foram nomeados mediante composição das variáveis destacadas em cada fator, conforme se pode observar no Diagrama 1.

Diagrama 1 - Fatores influenciadores da adoção de um método de custeio

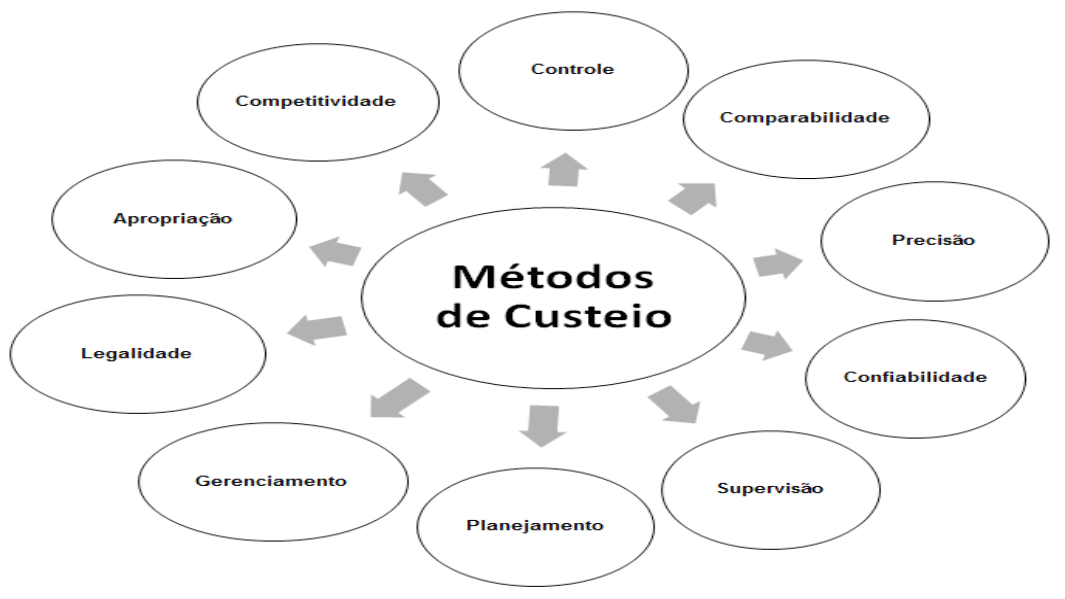

Fonte: os autores. 
No fator 1, nominado Competitividade, estão destacadas as variáveis vantagem competitiva (V05), flexibilizar o processo de tomada de decisões (V06), oferecer informações tempestivas e confiáveis (V09) e avaliar e controlar estratégias (V14). Diante dessa perspectiva, conclui-se que as variáveis agrupadas possuem relevância na gestão de custos da organização, pois o processo de adoção de um método de custeio representa como uma ferramenta que oferece às empresas informações que permitem manter no mercado produtos com qualidade e com menores custos. Assim, as informações observadas nesse fator podem contribuir significativamente para a competividade da organização diante das concorrentes (FROSSARD, 2003; NAKAGAWA, 1994).

No fator controle estão presentes as variáveis: margem de contribuição (V08), eliminar e reduzir custos que não adicionam valor ao produto (V11), acompanhamento das atividades operacionais e financeiras (V13), determinar as estimativas de custos (V15), acompanhamento na produção (V18), controle na produção (V19), aprimoramento dos controles da organização (V20) e realizar sistema de apuração do custo realizado (V34). Como se pode perceber, as variáveis destacadas nesse grupo contribuem diretamente ao processo de controle de diversas formas na organização, seja controlando custos, seja atividades. Na concepção de Martins (2003), a contabilidade de custos surgiu com a Revolução Industrial, quando a contabilidade financeira não conseguia suprir a necessidade das indústrias, e, atualmente, esse ramo da contabilidade visa produzir informações para os diversos níveis gerenciais de uma empresa, auxiliando em diversas funções de desempenho, entre elas o controle, que ocorre em diversas fases do processamento e alocação dos custos.

No fator comparabilidade são encontradas as variáveis: comparação do custo realizado e previsto (V16), controlar preços de insumos (V17), identificação dos custos por atividades (V22), alocação das despesas apenas nos demonstrativos de resultado (V24), apropriação dos custos indiretos (fixos e variáveis) no custo do produto (25) e delinear custo certo da produção (V32). As variáveis descritas no fator comparabilidade demostram a relevância que um método de custeio possui, assim como descreve Barbosa (2004). O autor destaca que a realização de comparações com diversos custos alocados no processo de produção de um bem ou serviço auxilia a empresa na gestão ao alcance dos objetivos pretendidos. Por intermédio dessa comparação pode-se observar variações ocorridas nos custos e, assim, corrigi-las.

Em seguida, tem-se o fator precisão, no qual se destacam cinco variáveis: não realiza rateios arbitrários (V21), reduz distorções no rateio dos custos indiretos (V23), apuração de desempenho unitário (V27), oferece maior rigor técnico na estimativa 
do custo (V33) e sistema de identificação e acumulação de custos (V35). Observa-se, dessa forma, que todas as variáveis descritas nesse fator estão diretamente ligadas à precisão; assim, esse fator torna-se de fundamental relevância, pois, de acordo com Callado e Callado (2000), as informações de custos devem ser utilizadas para diversas atividades na organização, como, por exemplo, no arbitramento dos rateios, na apuração do desempenho unitário, na estimativa de custos, no sistema de acumulação de custos, entre outros. A falta de precisão nessas atividades poderá comprometer a qualidade das decisões tomadas. Em seguida, destacam-se as variáveis presentes no fator confiabilidade.

O fator confiabilidade é composto por três variáveis, a margem de lucro desejada (V01), ponto de equilíbrio dos produtos (V03) e somente os custos variáveis são alocados aos produtos (V31). Dessa forma, toda a atenção é voltada para os custos variáveis, que tendem a ser alocados com maior grau de confiança. Assim, nesse fator destaca-se uma das principais características de um método de custeio, o processo de alocação de custos, que deve possuir a confiabilidade das informações, visando garantir a segurança das informações para o processo decisório e auxiliar a organização no alcance dos seus objetivos (MOTTA, 1997).

No fator apropriação são observadas duas variáveis: apropriação integral de todos os custos (26) e recuperar todos os custos. Assim, os métodos de custeio servem para normatizar cada etapa do processo de apropriação e apuração desenvolvida pelos sistemas de custeio, os quais se comportam como indicadores dos caminhos a serem seguidos para coleta, processamento e saída das informações para custeamento dos produtos (OSTROWSKI, 2005).

O fator legalidade é composto pelas variáveis: atende à legislação (V29) e está de acordo com os princípios Fundamentais da Contabilidade (V30), as quais destacam um dos pontos fortes que garantem a adoção de um método de custeio, que é atender à legislação fiscal brasileira e está de acordo com os princípios fundamentais da contabilidade aplicadas a custos, além de proporcionar melhores informações à gerência auxiliando na alocação dos custos de produção. Dessa forma, garantindo a legalidade na adoção do método de custeio, motivo este frequente para adoção de um método de custeio (FIORESE, 2005).

No que se refere ao grupo supervisão, encontram-se evidenciadas as variáveis acompanhamento na perspectiva do cliente (V10) e fragmenta a empresa em centro de custos (V12). Bornia (2002) afirma que por meio das informações contidas em um método de custeio é possível realizar supervisão de diversas atividades desenvolvidas na organização e nos vários setores destinados à produção. 
O fator gerenciamento é composto pelas variáveis ferramenta gerencial por meio dos direcionadores de custos (V04) e calcular a margem de contribuição (V07). Nascimento et al. (2003) afirmam que ao definir um método de custeio as indústrias buscam adotar um método que seja aplicável ao processo produtivo, este deve atender em grande parte ao aspecto de gerenciamento das diversas atividades, que auxilia nas etapas do setor de produção. Por fim, mas não menos relevante, encontra-se o fator planejamento.

O fator planejamento é composto pela variável planejamento de custos, volume e lucro (V02); de acordo com esta variável, pode-se perceber que ao adotar um método de custeio as indústrias buscam adotar um método que seja aplicável ao processo produtivo, este deve atender em grande parte ao aspecto gerencial como meio de subsidiar com informações úteis na formulação de orçamentos para fins de planejamento. O planejamento sempre se caracterizou como sendo uma das grandes preocupações para a organização, pois é por meio deste que são formulados possíveis direcionamentos que devem ser seguidos pela organização; assim, o planejamento do custo, volume e lucro é imprescindível nas empresas que atuam no setor industrial. Nesse sentido, a adoção de um método de custeio possibilita diversas formas de planejamento, auxiliando no gerenciamento, desenvolvimento ou adaptações das operações desempenhadas na entidade (MAHER, 2001).

Na pesquisa se identificaram, ainda, os fatores influenciadores da adoção de um método de custeio com maior grau de importância. Identificou-se que o fator que mais influencia a adoção de um método de custeio é a competitividade, em seguida vem o fator gerenciamento, o terceiro é representado pelo grupo de variáveis responsável por realizar o controle, o quarto fator enfoca a legalidade, o quinto é representado pelo planejamento, a apropriação foi considerada o sexto fator influente na adoção de um método de custeio, seguida pelo fator supervisão; já o fator comparabilidade ocupou a oitava posição no ranking de influência de adoção. O fator confiabilidade ocupou a nona posição de acordo com a percepção dos profissionais de contabilidade atuantes no setor industrial; por fim, o fator que menos influencia a adoção de um método de custeio é o fator precisão.

\section{CONCLUSÃO}

O presente estudo foi realizado com um grupo de profissionais contábeis atuantes no setor industrial. Pesquisar esse setor e identificar os fatores com maior grau de importância no processo de adoção de um método de custeio contribuiu para 
confirmar a literatura quanto à relevância desses métodos dentro de uma organização. Os métodos de custeio caracterizam-se como uma ferramenta fundamental dentro de uma organização, responsável pela separação dos custos e despesas, além de contabilizá-los e produzir diversos relatórios articulados que auxiliam nas tomadas de decisão. Dessa forma, o período de adoção de um método de custeio é uma fase em que a entidade deverá realizar uma análise detalhada dos objetivos pertinentes à empresa, buscando atender às necessidades dos diversos setores de forma eficaz e eficiente.

$\mathrm{Na}$ pesquisa atingiram-se os resultados de acordo com os objetivos estabelecidos, uma vez que se buscou identificar quais os fatores influenciadores da adoção de um método de custeio em empresas do setor industrial, tarefa definida como objetivo geral. Os objetivos específicos também foram atingidos, salientando que se buscava encontrar e nomear os agrupamentos de fatores influentes para a adoção de um método de custeio na ótica de profissionais de contabilidade com atuação no setor industrial. Foram identificados 10 fatores e nomeados de acordo com a natureza de cada variável pertencente a cada um deles, sendo os fatores competitividade, controle, comparabilidade, precisão, confiabilidade, apropriação, legalidade, supervisão gerenciamento e planejamento.

A pesquisa identificou, ainda, os fatores influenciadores da adoção de um método de custeio com maior grau de importância, uma vez que o fator que mais influencia a adoção de um método de custeio é o fator competitividade; em seguida, o segundo fator de influência é o fator gerenciamento, o terceiro é representado pelo grupo de variáveis responsável por realizar o controle, o quarto fator enfoca a legalidade e o quinto fator representado pelo planejamento. A apropriação foi considerada o sexto fator influente na adoção de um método de custeio, seguido pelo fator supervisão, já o fator comparabilidade ocupou a oitava posição no ranking de influência de adoção. O fator confiabilidade ocupou a nona posição de acordo com a percepção dos profissionais de contabilidade atuantes setor industrial; por fim, o fator que menos influencia na adoção de um método de custeio é o fator precisão.

Assim, o estudo contribuiu no sentido de orientar a empresa no momento da adoção de um método de custeio, uma vez que os fatores considerados nesse momento visam atender às necessidades reais da organização. Outro aspecto relevante demonstrado na presente pesquisa é que o fator legalidade, composto pelas variáveis aceita pela legislação fiscal e está de acordo com os princípios fundamentais da contabilidade, não possui forte relevância no processo de adoção de um método de custeio, uma vez que é o quarto fator de influência, demonstrando com essa posição que as organizações estão mais preocupadas em atender às expectativas e necessidades dos 
diversos setores, possuindo uma vantagem competitiva diante dos concorrentes que ainda possuem a contabilidade como um instrumento de obrigatoriedade e não para auxiliar na gestão da organização.

Por fim, destacam-se as limitações e as recomendações para trabalhos futuros. Os resultados deste estudo limitam-se às empresas do setor industrial, não sendo inseridos outros universos ou setores, o que impede a sua generalização. Contudo, o presente trabalho torna-se relevante, na medida em que traz a utilidade das informações contábeis no processo de gestão de uma organização, nos aspectos de planejamento, controle e execução das diversas atividades e setores. Diante de tal relevância, sugere-se a utilização deste estudo como elemento norteador para pesquisas futuras de mesmo gênero, realizando a análise das variáveis influenciadoras da adoção do método de custeio identificadas nesta pesquisa em outros setores de atuação, de maneira a integrar empresas do mesmo setor econômico e/ou segmentos diferentes.

\section{REFERÊNCIAS}

AZEVEDO, A. P. F.; GOUVÊA, J. B.; OLIVEIRA, U. R. de. Custeio por absorção x custeio ABC. In: SIMPÓSIO DE EXCELÊNCIA EM GESTÃO E TECNOLOGIA, 3., 2006, Resende. Anais... Resende, 2006.

BAKER, J. Activity-based costing and activity-based management: for healthcare. [S.l.]: Aspen Publishers, 1998.

BARBOSA, E. S. Proposta de sistemática para avaliação e controle de custos em propriedades rurais: o caso de uma empresa de criação de gado. 2004. Dissertação (Mestrado em Engenharia)-Universidade Federal do Rio Grande do Sul, Porto Alegre, 2004.

BARNEY, J. B.; CLARK, D. N. Resource-based theory: creating and sustaining competitive advantage. New York: Oxford University Press, 2007.

BLOCHER, E. J.; STOUT, D. E.; COKINS, G. Cost management: a strategic emphasis. 6. ed. New York: McGraw-Hill/Irwin, 2013.

BORNIA, A. C. Análise geral de custos - aplicação em empresas modernas. 1. ed. Porto Alegre: Bookman, 2002.

BRIMSON, J. A. Contabilidades por atividades. São Paulo: Atlas, 1996. 
BRUNI, A. L.; FAMÁ, R. Gestão de custos e formação de preços: com aplicações na calculadora HP12C e Excel. 5. ed. 2. reimpr. São Paulo: Atlas, 2009.

CALLADO, A. A. C.; CALLADO, A. L. C. Gestão de custos para pequenas organizações industriais. UnB Contábil, Brasília, DF, v. 3, n. 1, p. 127-141, 2000.

CARARETO, E. S. et al. Gestão estratégica de custos: custos na tomada de decisão. Revista de Economia de UEG, Anápolis, v. 2, n. 2, jul./dez. 2006.

CARMO, L. P. F. Análise de custos. 1. ed. Rio de Janeiro: Luis Paulo Faria Carmo, 2011.

CARVALHO, D. F. de. A contabilidade de custos e os métodos de custeio: uma análise da utilização gerencial da informação da contabilidade de custos pelas indústrias de autopeças da região metropolitana de Belo Horizonte. 2002. Dissertação (Mestrado em Ciências Contábeis)-Universidade Federal do Rio de Janeiro, Rio Janeiro, 2002.

CASTRO, P. de S. e. Aferição de custos em unidades básicas de saúde: revisão integrativa da literatura. 2011. Dissertação (Mestrado em Ciências)-Universidade de São Paulo, São Paulo, 2011.

CATELLI, A.; PEREIRA, C.; VASCONCELOS, M. Processo de gestão e sistemas de informações gerenciais. In: CATELLI, A. (Coord.). Controladoria: uma abordagem da gestão econômica. São Paulo: Atlas, 2001.

COLLIS, D. J.; MONTGOMERY, C. A. Competing on resources. Harvard Business Review, USA, v. 86, i. 7-8, p. 140, July/Aug. 2008.

COSTA, R. P. da. Proposta de modelo e implementação de um sistema de apoio a decisão em pequenas empresas. 1998. Tese (Doutorado)-Universidade de São Paulo, São Paulo, 1998.

CRUZ, J. B. Proposta de modelo de formação de preços em indústrias de bens de capital sob encomenda. 2010. Dissertação (Mestrado em Engenharia)-Escola Politécnica da Universidade de São Paulo, São Paulo, 2010.

ESTEVES, J. M. da S. Avaliação comparativa do custeio baseado em atividades e do custeio variável: um estudo de caso no IPEN. 2010. Dissertação (Mestrado em Ciências)-Instituto de Pesquisas Energéticas e Nucleares, São Paulo, 2010. 
FADANELLI, V. G. A utilização do método da unidade de esforço de produção como modelo de gestão de custos: O caso de uma indústria metalúrgica. 187 p. Dissertação (Mestrado em Engenharia de Produção)-Universidade Federal do Rio Grande do Sul, Porto Alegre, 2007.

FIORESE, A. Um estudo da aplicação de diferentes métodos de custeio em indústria metalúrgica de pequeno porte. 143 p. Dissertação (Mestrado em Ciências Contábeis)-Universidade Regional de Blumenau, Blumenau, 2005.

FROSSARD, A. C. P. Uma contribuição ao estudo dos métodos de custeio tradicionais e do método de custeio baseado em atividade (ABC) quanto a sua aplicação numa empresa pesqueira cearense para fins de evidenciação de resultado. 2003. Dissertação (Mestrado em Controladoria e Contabilidade)-Universidade de São Paulo, São Paulo, 2003.

GARRISON, R. H.; NOREEN, E. W. Contabilidade gerencial. 9. ed. Rio de Janeiro: LTC, 2001.

GONÇALVES, R. C. de M. G.; PROCÓPIO, A. M.; CONCENZA, V. A. Diferentes métodos de custeio e utilidade, confiabilidade e valor feedback da informação de custo. Revista de Contabilidade do Conselho Regional de São Paulo, São Paulo, ano 2, n. 4, mar. 1998.

HAIR JÚNIOR, J. et al. Análise multivariada de dados. 6. ed. Porto Alegre: Bookman, 2009.

LONGENECKER, J. G.; MOORE, C. W.; PETTY, J. W. Administração de pequenas empresas: ênfase na gerência empresarial. São Paulo: Makron Books, 1997.

LOURENÇO, J. F. de O. Modelo de custeio baseado em atividade - ABC - aplicado em um hospital. 2009. Dissertação (Mestrado em Engenharia)-Universidade de São Paulo, São Paulo, 2009.

KASPCZAK, M. C. de M.; SCANDELARI, L.; FRANCISCO, A. C. de. Sistema de custos: importância para tomada de decisões. In: ENCONTRO DE ENGENHARIA E TECNOLOGIA DOS CAMPOS GERAIS, 2., 2008, Campo Gerais. Anais... Campo Gerais, 2008.

KRAEMER, T. H. Discussão de um sistema de custeio adaptado às exigências da nova competição global. 2004. Dissertação (Mestrado em Engenharia)-Universidade Federal do Rio Grande do Sul, Porto Alegre, 2004. 
KOHLER, E. L. A dictionary for accountants. 5. ed. New Jersey: Prentice-Hall, 1975.

MAHER, M. Contabilidade de custos: criando valor para a administração. São Paulo: Atlas, 2001.

MARCOS, J. S.; NAIA, P. A contabilidade analítica, estudos provisionais e formação no século XXI. In: ENCONTRO IBERO AMERICANO DE CONTABILIDADE DE GESTÃO DA UNIVERSIDADE DE AVEIRO, 1., 2001, Valencia. Anais... Valencia, 2001.

MARTINS, E. Contabilidade de custos. 9. ed. São Paulo: Atlas, 2003.

MAUAD, L. G. A.; PAMPLONA, E. de O. ABC/ABM e BSC - Como essas ferramentas podem se tornar poderosas aliadas dos tomadores de decisão das empresas. In: CONGRESSO INTERNACIONAL DE COSTOS, 7., 2003, Punta Del Leste. Anais... Punta Del Leste, 2003.

MEGLIORINI, E. Custos análise e gestão. 2. ed. São Paulo: Pearson Prentice Hall, 2007.

MORELLI, Sergio. Gestão de custos em projetos uma aplicação prática do uso do EVMS. 2007. Dissertação (Mestrado em Engenharia)-Universidade de São Paulo, São Paulo, 2007.

MOTTA, F. G. Fatores condicionantes na adoção de métodos de custeio em pequenas empresas: um estudo multicasos em empresas do setor metal-mecânico de São Carlos - SP. 2000. Dissertação (Mestrado em Engenharia de Produção)-Universidade de São Paulo, São Carlos, 2000.

MOTTA, J. Decisões de preço em clima de incerteza: uma contribuição da análise Bayesiana. Revista de Administração de Empresas, São Paulo, p. 31-46, abr./jun. 1997.

MOROZINI, J. F.; PINTO, Marcos Moreira; GUTH, Sergio Cavagnoli. O custeio ABC em empresas comerciais: um modelo de aplicação. In: CONGRESSO BRASILEIRO DE CUSTOS, 2003, Gaurapari. Anais... Guarapari, 2003.

MOSCOVE, Stephen A.; SIMKIN, Mark G.; BAGRANOFF, Nancy A. Sistemas de informações contábeis. São Paulo: Atlas, 2002.

NAKAGAWA, M. Custeio baseado em atividades. São Paulo: Atlas, 1994. 
NASCIMENTO, J. M. do. Custos: planejamento, controle e gestão na economia globalizada. 2. ed. São Paulo: Atlas, 2001.

NASCIMENTO, Cristiano do Nascimento; GALLON, Alessandra Vasconcelos; GASPARETTO, Valdirene; PFITSCHER, Elisete Dahmer. Aplicação da contabilidade de custos na atividade agrícola. In: CONGRESSO BRASILEIRO DE CUSTOS, 15., 2008, Curitiba, Anais... Curitiba, 2008.

GASPARETTO, V.; PFITSCHER, E. D. Aplicação da contabilidade de custos na atividade agrícola. In: CONGRESSO BRASILEIRO DE CUSTOS, 15., 2008, Curitiba. Anais... Curitiba, 2008.

O’GUIN, M. C. The complete guide to activity-based costing. New Jersey: Prentice Hall, 1991.

OSTROWSKI, M. C. B. Métodos de custeio como instrumento gerencial nas Instituições do Sistema ACAFE - Associação catarinense das Fundações Educacionais. 2005. Dissertação (Mestrado em Ciências Contábeis)-Universidade Regional de Blumenau, Blumenau, 2005.

PANARELLA, P. J. M. Gestão e mensuração de custos: semelhanças e divergências entre a microeconomia e a contabilidade gerencial. 2010. Dissertação (Mestrado em Controladoria e Contabilidade)-Universidade de São Paulo, São Paulo, 2010.

PEREZ JÚNIOR, J. H.; OLIVEIRA, L. M. de; COSTA, R. G. Gestão estratégica de custos. 2. ed. São Paulo: Atlas, 2001.

\section{PERIASAMY, P. A textbook of financial constant management accounting.}

Mumbai: Department of Business Management, Himalaya Publishing House, 2010.

POMPERMAYER, C. B. Modelo conceitual de custos para estruturas organizacionais. In: CONGRESSO BRASILEIRO DE CUSTOS, 2000, Recife. Anais... Recife: Universidade Federal de Pernambuco, 2000.

REBELATTO, D. N; ARAMAYO, J. L. S.; ALMEIDA, M. R. O custeio por absorção como ferramenta de decisão para uma empresa no setor agroindustrial: o caso da indústria de polpa de coco. Revista GEPROS - Gestão da Produção, Operações e Sistemas, Bauru: Departamento de Engenharia de Produção da Faculdade de Engenharia da Unesp, ano 1, n. 3, 2006. 
ROBLES JUNIOR, Antônio. Contabilidade de Custo: temas atuais. [S.I.], Juruá, Parana, 2009.

SCIGLIANO, Bruno Salman. Desenvolvimento de um sistema de gestão de custos em uma empresa de embalagens metálicas. 2011. Monografia (Especialização em Engenharia de Produção)-Universidade de São Paulo, São Paulo, 2011.

ROSA, E. B. Indicadores de desempenho e sistema ABC o uso de indicadores e das atividades de manutenção. 2006. Tese (Doutorado em Engenharia)-Universidade de São Paulo, São Paulo, 2006.

SILVA, J. M. X. da. Gestão de custos em instituições hospitalares: análise qualitativa dos sistemas de custeamento adotados. 2011. Dissertação (Mestrado em Administração)-Universidade Potiguar, Natal, 2011.

SOUZA, A. A. de; AVELAR, E. A. A.; PAVIONE, C. S. S. N. Custeio baseado em atividades: uma análise das pesquisas brasileiras desenvolvidas na primeira década do século XXI. In: ENCONTRO NACIONAL DA ANPAD, 35., 2011, Rio de Janeiro. Anais... Rio de Janeiro, 2011.

SOUZA, R. M. de S. Avaliação de custo, volume e lucro em micro e pequenas empresas comerciais: um estudo de caso. 2007. Dissertação (Mestrado em Engenharia de Produção)-Universidade Federal de Itajubá, Itajubá, 2007.

VANDERBECK, E. J.; NAGY, C. F. Contabilidade de custos. 10. ed. Cengage Learning, 2001.

WICKERT, J. A. Análise da aplicação de diferentes métodos de custeio em uma sociedade cooperativa de produção agrícola. 2004. Dissertação (Mestrado em Ciências Contábeis)-Universidade Regional de Blumenau, Blumenau, 2004. 
Como citar este artigo:

\section{ABNT}

COSTA, Wenyca Preston Leite Batista da et al. Fatores influenciadores da adoção de um método de costing na perspectiva de profissionais em contabilidade com a atuação no setor industrial. RACE, Revista de Administração, Contabilidade e Economia, Joaçaba: Ed. Unoesc, v. 15, n. 3, p. 1169-1192, set./dez. 2016. Disponível em: <http://editora.unoesc.edu.br/index.php/race>. Acesso em: dia/mês/ano.
APA
Costa, W. P. L. B. da., Silva, J. D. da., Leone, R. J., Pessoa, M. N. M., \& Silva, S. L. P. (2016). Fatores influenciadores da adoção de um método de costing na perspectiva de profissionais em contabilidade com a atuação no setor industrial. RACE, Revista de Administração, Contabilidade e Economia, 15(3), 1169-1192. Recuperado em dia/mês/ano, de http://editora.unoesc.edu.br/index.php/race 